\title{
How to Restore Endodontically Treated Posterior Teeth: A Conservative Approach
}

\author{
Ivana Kantardžić ${ }^{1}$, Larisa Blažić2 ${ }^{\text {, Darko Vasiljević3 }}$, Djordje Petrović \\ ${ }^{1}$ Dental Department, Faculty of Medicine, University of Novi Sad, Novi Sad, Serbia; \\ ${ }^{2}$ Clinic of Dentistry of Vojvodina, Faculty of Medicine, University of Novi Sad, Novi Sad, Serbia; \\ 3 Institute of Physics, University of Belgrade, Belgrade, Serbia
}

\begin{abstract}
SUMMARY
Reconstruction of endodontically treated teeth is common procedure in everyday clinical practice. It has great impact on prognosis of endodontically treated teeth, however, there is no consensus regarding the most predictable restorative procedure. Widely accepted procedure has included the use of post and core and crown. Nowadays, sound tooth structure preservation has become one of the most influencing factors in terms of survival rate of treated teeth. Therefore, direct restorations have become more advantageous as compared to crowns. This article is a review about conservative reconstruction of endodontically treated posterior teeth. The purpose was to give the guidelines for clinicians how to choose the most successful therapeutic procedure for each individual case.
\end{abstract}

Keywords: endodontically treated teeth; premolar; molar; resin composite; amalgam; restoration

\section{INTRODUCTION}

Restoration of endodontically treated teeth is common procedure in everyday clinical practice. Despite the extensive research done on this subject, the answer about the restorative procedure that gives the greatest success remained controversial [1-4]. The restoration of endodontically treated teeth may be performed using different techniques, however, general recommendation for either conservative or prosthodontic restorative procedure has not been established $[5,6,7]$. Decision making usually includes a combination of therapeutic approach and financial capability of the patient. Some objective factors (tooth type, position and function in the dental arch) may have an influence on survival rate of restored endodontically treated teeth and should be considered when planning treatment $[8,9,10]$.

Earlier belief that endodontically treated teeth dry over time, become more brittle and susceptible to fracture was the reason that most common approach for restoration included post and core and crown placement to "strengthen" the tooth [11]. On the other hand, Papa et al. [12] reported no significant difference in moisture content of vital and endodontically treated teeth. Also, Sedgley and Messer [13] did not find any difference in biomechanical properties between endodontically treated and vital teeth.

Endodontically treated teeth usually lose substantial tooth structure from caries, previous restorations, and endodontic procedure. Comparing the loss of hard tooth tissue volume by various treatment procedures (caries removal, access cavity preparation, root canal prepara- tion, post and cast-post space preparation), it was found that the great amount of hard tissue volume was lost in every stage of treatment procedure with the exception of root canal preparation stage [14]. Fernandes and Dessai [15] suggested that loss of tooth structure associated with caries and access preparation make avital teeth prone to fracture, rather than structural changes in dentin. Because of that, preservation of sound tooth structure is regarded as one of the most important aspects in increasing survival rate of endodontically treated teeth $[7,8]$. From this perspective, direct restorations seem to be more advantageous over crowns, since crown preparation is associated with extensive loss of tooth structure, and consequently higher possibility for failure.

\section{RESIN COMPOSITE RESTORATION}

Resin composite materials are currently used in 50\% of all posterior direct restorations [16]. They have an advantage of bonding to tooth structure which might strengthen a tooth [17]. Hence, despite the longstanding application of these materials in clinical practice, polymerization shrinkage has still been a serious drawback, resulting in cuspal stress and strain with subsequent debonding, microleakage and recurrent caries [18-22]. An extensive research has been undertaken in attempt to minimize this problem. As a result, different clinical approaches have been advocated in order to reduce or overcome the effect of polymerization contraction stress. There is an agreement that composites with low shrinkage [23], incremental layering [24], flow composites and 
glass-ionomer materials as a liner/base $[5,25]$ reduce negative influence of polymerization shrinkage. Also, the curing regime has significant influence on polymerization shrinkage [26]. Although the „soft-start” light-curing protocols has not been shown better when compared to standard curing regime [27, 28], Pantelic et al. [29] found that slower method, with low power density is preferred in dental practice.

Beside polymerization shrinkage, cavity preparation design also has a great impact on the survival rate of endodontically treated posterior teeth, especially in extensive mesio-occluso-distal (MOD) cavities. Sometimes cuspal reduction of $2.5 \mathrm{~mm}$ minimum is recommended [30]. Severely damaged endodontically treated premolars with substantial loss of tooth structure larger than MOD, could be reconstructed with a direct composite resin endocrown $[31,32]$. This type of restoration substitutes complete crown and extends into the root canal for $2 \mathrm{~mm}$.

Recently, a new restorative technique for conservative restoration of severely damaged endodontically treated posterior teeth was presented [33,34]. It involves the use of polyethylene fibers with resin composite which provides similar stress distribution as in a sound tooth. This technique was clinically approved for the restoration of fractured cusps in endodontically treated teeth because it was shown to create strong bridge between the tooth structure and restorative material $[35,36]$.

The use of posts combined with direct composite restorations in endodontically treated teeth still remains controversial among dental practitioners. While in one study it was found that post in premolars with class II cavities significantly increased tooth fracture resistance [37], in another experimental study post placement in severely damaged endodontically treated premolars did not increase the resistance to fracture in cases where direct resin composite crown was applied [31]. Even though many clinicians believe that post reinforces endodontically treated teeth $[38,39]$, opposite opinion had been found in the scientific literature [1]. Accordingly, posts have been suggested only as core retention in the tooth with extensive loss ( $>50 \%)$ of coronal structure [1, $4,40]$.

Resin composite materials can be used for direct restorations of endodontically treated teeth with excessive loss of tooth structure at a relatively low cost and as aesthetic alternative to cuspal coverage restorations [41]. Mannoci et al. [2] reported similar results. They compared failure rate of endodontically treated premolars restored with fiber posts and direct composite restorations versus post and metal-ceramic crown treatment and three years after, no difference in clinical performance of the two treatment procedures was found.

Longevity of resin composite restorations was evaluated by Kubo [42]. He selected 21 prospective study and 9 retrospective studies about the clinical performance of resin composite restorations placed in permanent teeth over 8 years or more during the period 1990-2009. After ten years survival rate of class II composite restorations ranged from $58.3 \%$ to $100 \%$ in prospective studies and from $55.1 \%$ to $89.7 \%$ in retrospective studies. The overall success rate was $60 \%$. The lowest values were obtained from restorations placed by inexperienced operators or general practitioners indicating that a skilled operator can add to the clinical survival of resin composite restorations.

\section{AMALGAM RESTORATIONS}

Although some dental schools have reduced or no longer teach amalgam restorations [43,44], the use of this material in clinical practice in Serbia is still frequent. For the restoration of endodontically treated posterior teeth amalgam has been found as inexpensive treatment option, less demanding and time consuming as compared to a direct resin composite restoration $[6,16]$.

Previous studies have reported inconsistent results regarding long-term performance of amalgam when compared to other dental materials. In one study amalgam restorations had survival time of 12.8 years [45]. Compared to 14.6 years of survival for crowns, and 7.8 years for resin composite restorations, amalgam restorations should be recommended as an alternative to crowns. On the opposite, another 5-years retrospective study indicated better performance of direct composite restorations over amalgam [7]. The success rate for composite restorations was $96 \%$ after 1 year, $90 \%$ after 2 years, and $38 \%$ after 5 years, while for amalgam it was $93 \%$, $77 \%$ and $17 \%$, respectively. In a randomized controlled trial the clinical success rate for endodontically treated premolars restored with amalgam restorations was compared to the combination of fiber post and direct resin composite [46]. Although the overall failure rate was not significantly different for these two types of restorations, the use of fiber posts and direct resin composite restorations was found more effective than amalgam in preventing root fracture, but less effective in preventing secondary caries.

Additionally, Soares et al. [47] suggested that amalgam restorations have not been good option to restore endodontically treated teeth with MOD cavity due to its biomechanical behavior, providing fracture resistance only $36.2 \%$ of value provided by a sound tooth. However, if used for a restoration when cavity preparation includes cuspal coverage, amalgam may resist fracture more effectively [6].

\section{CONCLUSION}

There is no consensus regarding the procedure that gives the greatest success in restoration of endodontically treated posterior teeth. It seems that the amount of preserved coronal tooth structure has the most significant influence on the long-term survival of these teeth. Therefore, contemporary approach in restorative dentistry should include less invasive treatment procedures. Accordingly, the following may be suggested: 1) As cavity preparation for amalgam might require removal of additional amount of sound tooth structure, with regards to 
biomechanical considerations, bonded restorative materials are more favorable for restoration of endodontically treated posterior teeth, especially those with extensive cavities. However, clinicians should strictly follow manufacturer's instructions for their use, 2) Posts should be used only in endodontically treated teeth with extensive loss ( $>50 \%)$ of coronal structure; 3 ) Direct composite resin endocrown is favorable treatment option for severely damaged endodontically treated premolars.

\section{ACKNOWLEDGMENT}

This work was realized with the support of the Serbian Ministry of Science and Technological Development under contract III45016.

\section{REFERENCES}

1. Faria A, Rodrigues R, Antunes R, de Mattos M, Ribeiro R. Endodontically treated teeth: characteristics and considerations to restore them. J Prosthodont Res. 2010; 55:69-74.

2. Mannocci F, Bertelli E, Sherriff M, Watson TF, Pitt Ford P. Threeyear clinical comparison of survival of endodontically treated teeth restored with either full cast coverage or with direct composite restoration. Int End J. 2009; 42:401-5.

3. Ferrari M, Cagidiaco M, Grandini S, De Sanctis M, Goracci C. Post placement affects survival of endodontically treated premolars. J Dent Res. 2007; 86:729-34.

4. Vidyashree V, Venkatesh V. Current concept in the restoration of endodontically treated teeth. I Indian Prosthodont Soc. 2006; 6:63-7.

5. Taha N, Palamara J, Messer H. Fracture strength and fracture patterns of root filled teeth restored with direct resin restorations. J Dent. 2011; 39:527-35.

6. Assif D, Nissan J, Gafni Y, Gordon M. Assessment of the resistance to fracture of endodontically treated molars restored with amalgam. J Prosthet Dent. 2003; 89:462-5.

7. Nagasiri R, Chitmongkolsuk S. Long-term survival of endodontically treated molars without crown coverage: a retrospective cohort study. J Prosthet Dent. 2005; 93:164-70.

8. Naumann M, Blankenstein F, Dietrich T. Survival of glass fibre reinforced composite post restorations after 2 years - an observational clinical study. J Dent. 2005; 33:305-12.

9. Naumann M, Blankenstein F, Kiessling S, Dietrich T. Risk factors for failure of glass fiber-reinforced composite post restorations: a prospective observational clinical study. Eur J Oral Sci. 2005; 113:519-24.

10. Petrović $Đ$, Horvat-Banić S. Electromyographic activity of the temporal and masseter muscles at different occlusal positions. Med Pregl. 2007; 60:134-9.

11. Rivera EM, Yamauchi M. Site comparison of dentine collagen crosslinks from extracted human teeth. Arch Oral Biol. 1993; 38:541-6.

12. Papa J, Cain C, Messer H. Moisture content of vital vs endodontically treated teeth. Endod Dent Traumatol. 1994; 10:91-3.

13. Sedgley SM, Messer $\mathrm{HH}$. Are endodontically treated teeth more brittle? J Endod. 1992; 18:332-5.

14. Ikram OH, Patel S, Sauro S, Mannocci F. Micro-computed tomography of tooth tissue volume changes following endodontic procedures and post space preparation. Int End J. 2009; 42:1071-6.

15. Fernandes AS, Dessai GS. Factors affecting the fracture resistance of post-core reconstructed teeth: a review. Int J Prosthodont. 2001; 14:355-63.

16. Sadowsky SJ. An overview of treatment considerations for esthetic restorations: a review of the literature.J) Prosthet Dent. 2006; 96:433-42.

17. Soares P, Santos-Filho P, Queiroz E, Araujo C, Campos R, Araujo $C$, et al. Fracture resistance and stress distribution in endodontically treated maxillary premolars restored with composite resin. J Prosthodont. 2008; 17:114-9.
18. Pantelić D, Blažić L, Savić-Šević S, Murić B, Vasiljević D, Panić B, et al. Holographic measurement of dental tissue contraction and stress, due to postpolymerization reaction. Acta Physica Polonica A. 2007; 112:1157-60.

19. Pantelić D, Blažić L, Savić-Šević S, Murić B, Vasiljević D, Panić B, et al. Real-time measurement of internal stress of dental tissue using holography. Optics Express. 2007; 15:6823-30.

20. Kantardžić I, Vasiljević D, Blažić L, Puškar T, Tasić M. Computedtomography scan-based finite element analysis of stress distribution in premolars restored with composite resin. Phys Scr. 2012; T146 [in press].

21. Ausiello P, Apicella A, Davidson CL. Effect of adhesive layer properties on stress distribution in composite restorations - a 3D finite element analysis. Dent Mater. 2002; 18:295-303.

22. Fleming G, Hall D, Shortall A, Burke F. Cuspal movement and microleakage in premolar teeth restored with posterior filling materials of varying reported volumetric shrinkage values. J Dent. 2005; 33:139-46.

23. Burke F, Crisp R, James A, Mackenzie L, Pal A, Sands P, et al. Two year clinical evaluation of a low-shrink resin composite material in UK general dental practices. Dent Mater. 2011; 27:622-30.

24. Park J, Chang J, Ferracane J, In Bog Lee. How should composite be layered to reduce shrinkage stress: incremental or bulk filling? Dent Mater. 2008; 24:1501-5.

25. Cara R, Fleming G, Palin W, Walmsley A, Burke F. Cuspal deflection and micro leakage in premolar teeth restored with resin-based composites with and without an intermediary flowable layer. J Dent. 2007; 35:482-9.

26. Marković $D$, Blažić $L$, Đurić $M$, Vučinić P, Blagojević $D$, Bajkin B. Current trends in clinical practice. Med Pregl. 2007; 60:663-8.

27. Blažić L, Živković S. Influence of "soft-start" polymerization on marginal sealing in resin composite restoration. Stomatološki glasnik Srbije. 2003; 50:59-64.

28. Visvanathan A, llie N, Hickel R, Kunzelmann K. The influence of curing times and light curing methods on the polymerization shrinkage stress of a shrinkage-optimized composite with hybrid-type prepolymer fillers. Dent Mater. 2007; 23:777-84.

29. Pantelić D, Savić-Šević S, Vasiljević D, Murić B, Blažić L, Nikolić M, et al. Holographic measurement of a tooth model and dental composite contraction. Materials and Manufacturing Processes. 2009; 24:1142-6.

30. Magne P, Knezevic A.Thickness of CAD-CAM composite resin overlays influences fatigue resistance of endodontically treated premolars. Dent Mater. 2009; 25:1264-8.

31. Fokkinga W, Le Bell A, Kreulen C, Lassila L, Vallittu P, Creugers N. Ex vivo fracture resistance of direct resin composite complete crowns with and without posts on maxillary premolars. Int End J. 2005; 38:230-7.

32. Stricker E, Göhring T. Influence of different posts and cores on marginal adaptation, fracture resistance, and fracture mode of composite resin crowns on human mandibular premolars. An in vitro study. J Dent. 2006; 34:326-35.

33. Sengun A, Cobankara F, Orucoglu H. Effect of a new restoration technique on fracture resistance of endodontically treated teeth. Dent Traumatol. 2008; 24:214-9.

34. Eraslan OZ, Eraslan OG, Eskitascioglu G, Belli S. Conservative restoration of severly damaged endodontically treated premolar teeth: A FEM study. Clin Oral Invest. 2011; 15:403-8.

35. Deliperi S, Bardwell D, Coiana C. Reconstruction of devital teeth using direct fiber-reinforced composite resins: a case report. J Adhes Dent. 2005; 7:1-7.

36. Deliperi S. Direct fiber-reinforced composite restoration in an endodontically-treated molar: a three-year case report. Oper Dent. 2008; 33:209-14.

37. Nothdurft F, Seidel E, Gebhart F, Naumann M, Motter P, Pospiech P. The fracture behavior of premolar teeth with class II cavities restored by both direct composite restorations and endodontic post systems. J Dent. 2008; 36:444-9.

38. Naumann M, Kiessling S, Seemann R. Treatment concepts for restoration of endodontically treated teeth: a nationwide survey of dentists in Germany. J Prosteht Dent. 2006; 96:332-8.

39. Eckerbom M, Magnusson T. Restoring endodontically treated teeth: a survey of current opinions among board-certified prosthodon- 
tists and general dental practitioners in Sweden. Int J Prosthodont. 2001; 14:245-9.

40. Puškar T, Blažić L. A review of post and core application in clinical practice. Stomatološki informator. 2005; 11(16):17-23.

41. Stojičić S, Jevremović D, Živković S. Reconstruction of endodontically treated teeth after excessive loss of tooth structure-two case reports. Stomatološki glasnik Srbije. 2009; 56:40-8.

42. Kubo S. Longevity of resin composite restorations. Japanese Dental Science Review. 2011; 47:43-55.

43. Lynch CD, Fraizer KB, McConnell RJ, Blum IR, Wilson NHF. State of the art techniques in operative dentistry: contemporary teaching of posterior composites in UK and Irish dental schools. Br Dent J. 2010; 209:129-36.

44. Roeters F, Opdam N, Loomans B. The amalgam free school. J Dent. 2004; 32:371-7.
45. Van Nieuwenhuysen J, D'Hoore W, Carvalho J, Qvist V. Long-term evaluation of extensive restorations in permanent teeth. J Dent. 2003; 31:395-405.

46. Mannocci F, Qualtrough A, Worthington H, Watson T, Pitt Ford T. Randomized clinical comparison of endodontically treated teeth restored with amalgam or with fiber posts and resin composite: five-year results. Oper Dent. 2005; 30:9-15.

47. Soares P, Santos-Filho P, Martins L, Soares C. Influence of restorative technique on the biomechanical behavior of endodontically treated maxillary premolars. Part I: Fracture resistance and fracture mode. J Prosthet Dent. 2008; 99:30-7.

Received: 01/02/2012 • Accepted: 04/05/2012 


\title{
Savremeni aspekti konzervativne rekonstrukcije endodontski lečenih bočnih zuba
}

\author{
Ivana Kantardžić1, Larisa Blažić2, Darko Vasiljević3 ${ }^{3}$ Đorđe Petrović2 \\ ${ }^{1}$ Katedra za stomatologiju, Medicinski fakultet, Univerzitet u Novom Sadu, Novi Sad, Srbija; \\ ${ }^{2}$ Klinika za stomatologiju Vojvodine, Medicinski fakultet, Univerzitet u Novom Sadu, Novi Sad, Srbija; \\ Institut za fiziku, Univerzitet u Beogradu, Beograd, Srbija
}

\begin{abstract}
KRATAK SADRŽAJ
Rekonstrukcija endodontski lečenih zuba je terapijski postupak koji se svakodnevno vrši u kliničkoj praksi. lako konačna rekonstrukcija zubne krunice značajno utiče na prognozu endodontski lečenih zuba, ne postoji jedinstven stav o tome koji tip rekonstrukcije obezbeđuje najpovoljniji klinički uspeh. Ranije su endodontski lečeni zubi najčešće sanirani livenom nadogradnjom i metalokeramičkom krunicom. Danas savremena restaurativna stomatologija ističe očuvanje zdrave zubne supstance kao jedan od najznačajnijih faktora koji doprinose kliničkoj dugotrajnosti endodontski lečenih zuba. Zbog toga se konzervativne direktne restauracije smatraju povoljnijim od protetičkih. Cilj ovog rada bio je da se prikažu noviji pristupi u konzervativnoj rekonstrukciji endodontski lečenih bočnih zuba i smernice kojima se treba voditi pri izboru terapijskog postupka.
\end{abstract}

Ključne reči: endodontski lečeni zubi; premolar; molar; kompozit; amalgam; restauracija

\section{UVOD}

Rekonstrukcija endodontski lečenih zuba je terapijski postupak koji se svakodnevno vrši u kliničkoj praksi. Mada je ova tematika bila predmet mnogobrojnih istraživanja, i dalje ne postoji jedinstven stav u vezi s izborom najadekvatnijeg načina nadoknade izgubljenih zubnih tkiva [1-4]. Iako postoji više mogućnosti izvođenja rekonstrukcije endodontski lečenih zuba, zasad nisu definisane jasne smernice koje bi terapeuta opredelile za konzervativni, odnosno protetički terapijski postupak $[5,6$, 7]. Odluka se najčešće donosi na osnovu znanja i iskustva terapeuta, kao i finansijskih mogućnosti pacijenta. Ipak, grupa autora je istakla da neki osnovni faktori, kao što su vrsta zuba, položaj i funkcija u zubnom nizu, imaju uticaja na dugovečnost endodontski lečenih zuba, te ih stoga treba uzeti u razmatranje prilikom planiranja terapijskog postupka $[8,9,10]$.

U prethodnom periodu preovladavao je stav da kod endodontski lečenih zuba dolazi do dehidratacije, što je sam zub činilo krtim i podložnijim lomu u odnosu na vitalne zube [11]. Usled toga, endodontski lečeni zubi su ojačavani livenom nadogradnjom preko koje se izrađivala protetička krunica. Papa (Papa) i saradnici [12], međutim, nisu ustanovili razliku u hidriranosti vitalnih i endodontski lečenih zuba, dok Sedžli (Sedgly) i Meser (Messer) [13] nisu utvrdili značajne razlike u biomehaničkim osobinama dentina vitalnih i endodontski lečenih zuba.

Endodontski lečene zube najčešće odlikuje značajan gubitak tvrde zubne supstance, bilo usled karijesa, prethodnih restauracija ili endodontskog tretmana. Poređenjem volumena izgubljenih tvrdih zubnih tkiva usled različitih postupaka u toku rada (uklanjanje karijesa, preparacija pristupnog kaviteta, kanala korena ili za pulparni kočić), zaključeno je da jedino postupak preparacije kanala korena ne dovodi do značajnog gubitka tvrde zubne supstance [14]. Fernandes (Fernandes) i Desai (Dessai) [15] su istakli da su avitalni zubi manje otporni na lomljenje usled gubitka tvrde zubne supstance uzrokovane karijesom, odnosno formiranjem pristupnog kaviteta, a ne usled promena u dentinu, kao što se ranije smatralo. U skladu s navedenim, očuvanje tvrde zubne supstance se nameće kao jedan od najznačajnijih faktora u obezbeđivanju kliničke dugotrajnosti endodontski le- čenih zuba [7, 8]. Posmatrano iz ovog ugla, konzervativnoj sanaciji endodontski lečenih zuba direktnim ispunima treba dati prednost nad protetičkim krunicama s obzirom na to da njihova izrada zahteva značajnije uklanjanje zubne strukture.

\section{REKONSTRUKCIJA ENDODONTSKI LEČENIH BOČNIH ZUBA KOMPOZITNIM SMOLAMA}

Prema podacima iz literature, kompozitne smole kao restaurativni materijali čine 50\% svih direktnih ispuna na bočnim zubima [16]. Osnovna prednost kompozitnih rekonstrukcija jeste adhezivno vezivanje sa zubnom supstancom preko gleđno-dentinskih adhezivnih sistema, koje može uticati na veću otpornost endodontski lečenih zuba [17]. Iako se ovi materijali u kliničkoj praksi primenjuju već više decenija, problem polimerizacione kontrakcije i sledstvene pojave napona i deformacija unutar zubnih tkiva, uz rizik od nastanka mikropukotine, odnosno sekundarnog karijesa, i dalje ostaje nerešen [18-22]. Da bi se prevazišao ovaj problem, obavljena su mnoga istraživanja, a kao rezultat predloženi su različiti klinički postupci za otklanjanje negativnih posledica polimerizacione kontrakcije. Stomatolozima su na raspolaganju kompozitne smole s malim stepenom kontrakcije [23], postavljanje materijala u slojevima [24], primena tečnih kompozita i glasjonomer cementa kao prvog sloja ili podloge $[5,25]$ ispod kompozitnih ispuna. Različiti režimi svetlosnoindukovane polimerizacije takođe značajno utiču na pojavu napona usled kontrakcije kompozitnog materijala [26]. Iako primena moduliranih svetlosnopolimerizujućih režima nije pokazala značajne prednosti u poređenju sa standardnim protokolima [27, 28], Pantelić i saradnici [29] preporučuju duže izlaganje svetlosnoj energiji uz primenu manjih iradijansi.

Osim polimerizacione kontrakcije, i dizajn preparacije kaviteta, naročito kada su u pitanju mezio-okluzo-distalni (MOD) kaviteti, značajno utiče na dugotrajnost endodontski lečenih bočnih zuba rekonstruisanih kompozitnim smolama. U ovakvim slučajevima neophodno je smanjiti kvržice zuba najmanje 2,5 mm [30]. Ukoliko postoji još izraženiji gubitak zubne supstance, pri rekonstrukcijama endodontski lečenih premo- 
lara moguće je izraditi tzv. endokrunicu. Ovakva vrsta restauracije širi se u kanal korena zuba $2 \mathrm{~mm}$ i zamenjuje čitavu krunicu zuba [31, 32].

Novija terapijska metoda koja se takođe primenjuje pri većem gubitku zubne supstance podrazumeva korišćenje polietilenskih vlakana u kombinaciji s kompozitnim smolama [33, 34]. Klinički je dokazano da je navedena vrsta restauracije dodatno efikasna pri rekonstrukciji endodontski lečenih zuba kod kojih postoji prelom kvržice, jer se primenom pomenutih vlakana ostvaruje jača veza između zubnih struktura i restaurativnog materijala $[35,36]$.

Primena pulparnih kočića uz direktnu rekonstrukciju kompozitnim smolama još jedno je pitanje u vezi s kojim su mišljenja stručnjaka podeljena. Dok jedna studija ukazuje na to da pulparni kočići značajno povećavaju otpornost na lomljenje endodontski lečenih premolara sa kavitetima druge klase rekonstruisanim kompozitnim smolama [37], druga studija pokazuje da kod direktne izrade kompozitne krunice na premolarima primena pulparnih kočića ne doprinosi kvalitetu restauracije [31]. Iako među stomatolozima praktičarima vlada uverenje da pulparni kočići čine endodontski lečene zube otpornijim $[38,39]$, naučna literatura podržava suprotan stav [1]. Naime, smatra se da pulparne kočiće treba koristiti samo pri većem gubitku zubne supstance $(>50 \%)[1,4,40]$.

Konzervativna rekonstrukcija endodontski lečenih zuba s izraženim gubitkom tvrdih struktura relativno je jeftin i estetski zadovoljavajući terapijski postupak u poređenju s izradom protetičkih zubnih nadoknada [41], što su u svojoj studiji potvrdili i Manoči (Mannocci) i saradnici [2]. Oni u kliničkim uslovima nisu uočili razlike kada su posle tri godine poredili kompozitne restauracije s pulparnim kočićem na endodontski lečenim zubima s metalokeramičkim krunicama i pulparnim kočićima.

Procenu kliničkog uspeha kompozitnih restauracija dao je i Kubo (Kubo) [42]. On je analizirao 21 prospektivno istraživanje i devet retrospektivnih studija o kliničkoj uspešnosti kompozitnih restauracija na stalnim zubima koje su trajale najmanje osam godina za period 1990-2009. godine. Desetogodišnja stopa uspešnosti za restauracije druge klase bila je 58,3-100\% u prospektivnim i 55,1-100\% u retrospektivnim studijama. Sveukupna stopa uspešnosti bila je $60 \%$. Najniže vrednosti uočene su za restauracije koje su izveli neiskusni terapeuti i opšti stomatolozi, što ukazuje na to da iskustvo i veština terapeuta značajno utiču na kliničku dugotrajnost kompozitnih restauracija.

\section{REKONSTRUKCIJA ENDODONTSKI LEČENIH BOČNIH ZUBA AMALGAMSKIM ISPUNIMA}

Primena amalgamskih ispuna u rekonstrukcijama kaviteta još je česta u Srbiji, mada se u pojedinim zemljama više ne vrši ni edukacija studenata stomatologije u vezi s primenom dentalnih amalgama $[43,44]$. Njihova primena u rekonstrukciji endodontski lečenih bočnih zuba (iako su estetski neodgovarajući materijali) relativno je jeftin terapijski postupak, koji je, u poređenju s izradom direktne kompozitne restauracije, manje tehnički i vremenski zahtevan $[6,16]$.

Ranija istraživanja su pokazala različite rezultate kliničke uspešnosti dentalnih amalgama u poređenju sa drugim dentalnim materijalima. Prema jednoj studiji, dugotrajnost amalgamskih ispuna je 12,8 godina [45]. U poređenju sa trajanjem od 14,6 godina metalokeramičkih krunica i 7,8 godina kompozitnih restauracija, može se zaključiti da su amalgamski, a ne kompozitni ispuni, odgovarajuća alternativa protetičkim nadoknadama. S druge strane, petogodišnja retrospektivna studija je ukazala na veću uspešnost direktnih kompozitnih restauracija [7]. Utvrđena stopa uspeha bila je $96 \%$ posle godinu dana, $90 \%$ posle dve godine i $38 \%$ posle tri godine, dok je za amalgamske ispune iznosila 93\%, 77\% i 17\%. Poređenjem kliničke uspešnosti primene dentalnog amalgama u rekonstrukciji endodontski lečenih zuba sa direktnim kompozitnim ispunima uz korišćenje kompozitnog pulparnog kočića, jedina uočena razlika bila je u tome što je kod kompozitnih materijala sekundarni karijes bio češći razlog neuspeha, dok je kod rekonstrukcija amalgamom neuspeh lečenja bio uzrokovan prelomom korena zuba [46].

Posmatrano sa biomehaničkog aspekta, Soareš (Soares) i saradnici [47] zaključili su da amalgamske restauracije nisu povoljno terapijsko rešenje kod endodontski lečenih bočnih zuba sa MOD kavitetom. Razlog je nedovoljna otpornost na lomljenje, koja je svega $36,2 \%$ u poređenju s otpornošću intaktnog zuba. Ipak, ukoliko se restauracijom obuhvate i kvržice zuba, može se obezbediti veća otpornost na lomljenje [6].

\section{ZAKLJUČAK}

U stručnoj i naučnoj javnosti zasad nema jedinstvenog stava o tome koji tip rekonstrukcije endodontski lečenih bočnih zuba obezbeđuje najpovoljniji klinički uspeh. Imajući u vidu da se očuvanje preostale tvrde zubne supstance smatra jednim od najvažnijih faktora koji doprinose uspešnosti terapijskog postupka i dugotrajnosti zubne nadoknade, savremena restaurativna stomatologija bi trebalo da favorizuje manje invazivne terapijske procedure. U skladu s tim, u kliničkom radu pri rekonstrukciji endodontski lečenih bočnih zuba prednost treba dati direktnim kompozitnim ispunima, naročito ako su u pitanju rekonstrukcije ekstenzivnih kaviteta. Pulparne kočiće treba koristiti samo kada je gubitak koronarne zubne strukture veći od 50\%. Izrada endokrunice od kompozitnog materijala je povoljno kliničko rešenje kod endodontski lečenih premolara s izraženim nedostatkom zubne supstance.

\section{NAPOMENA}

Rad je deo istraživanja realizovanog u okviru projekta „Generisanje i karakterizacija nano-fotonskih funkcionalnih struktura u biomedicini i informatici" (broj III45016), koji je finansiralo Ministarstvo za nauku i tehnološki razvoj Republike Srbije. 